\title{
CORRIGENDA
}

\section{Independence of familial transmission of mania and depression: results of the NIMH family study of affective spectrum disorders}

KR Merikangas, L Cui, L Heaton, E Nakamura, C Roca, J Ding, H Qin, W Guo, Y Yao-Shugart, C Zarate and J Angst

Molecular Psychiatry (2014) 19, 272; doi:10.1038/mp.2013.181; published online 24 December 2013

Correction to: Molecular Psychiatry, advance online publication, 15 October 2013; doi:10.1038/mp.2013.116
After the above article was published, the authors noted that the ninth author was listed incorrectly. The author's correct name is YY Shugart.

\section{Playing Super Mario induces structural brain plasticity: gray matter changes resulting from training with a commercial video game}

S Kühn, T Gleich, RC Lorenz, U Lindenberger and J Gallinat

Molecular Psychiatry (2014) 19, 272; doi:10.1038/mp.2013.169; published online 26 November 2013

Correction to: Molecular Psychiatry, advance online publication, 29 October 2013; doi:10.1038/mp.2013.120

Following publication of the above article, the authors noticed that there was an error in the first sentence of the Results section. The correct statement appears below.

On average, participants played $50.2 \mathrm{~h}(\mathrm{s.d} .=14.6)$ in total, amounting to about $50 \mathrm{~min}$ per day and obtained 74.7 (s.d. $=37.4)$ stars. 